\section{New directions for the Revista/Journal}

\author{
María L. Clark ${ }^{1}$
}

Those of you who have read the most recent issues of the Revista Panamericana de Salud Pública/Pan American Journal of Public Health will have noted an unprecedented event in the history of this publication: the creation of a new Editorial Board. Composed of ten renowned public health professionals and researchers from all the subregions of the Western Hemisphere, this advisory group assembled for the first time in Washington, D.C., on 5 and 6 October 2000 and met with the Revista/Journal staff and with high-level officials of the Pan American Health Organization (PAHO). The wealth of the contributions and the productivity of the discussions in that initial meeting met our highest expectations. In fact, deliberations on the journal had scarcely begun when it became clear that there was a need to first address a fundamental question: What is the Revista/Journal? In its direction and content, is it independent of the Organization to which it belongs, or is it primarily an institutional journal, intended to disseminate PAHO's policies and to convey scientific information filtered through the "lenses" of the Organization? But in the end the feeling was unanimous: the Revista/Journal cannot and should not be just one of those things or the other. Because of its special position between those two extremes, the Revista/Journal is unique and is able to provide readers something that no other public health journal from the Americas can.

The Revista/Journal is, on the one hand, a forum for the dissemination of the work of independent researchers, whose papers it subjects to rigorous peer review. On the other hand, its links with PAHO enable the Revista/Journal to offer its readers a select and balanced repertory of national experiences that can serve as models and sources of inspiration to other countries struggling to address their health problems and to improve their health systems and services. It is worth recalling that globalization has increasingly brought public health under the domain of a growing number of entities-the State, the corporate sector, the insurance industry, unilateral and bilateral organizations, research centers, the education sector, and organized civil society. In its role as an international organization that advises countries and offers technical assistance throughout the Region, PAHO's leadership position enables it to follow the pace at which our entire Hemisphere and each of its countries is advancing in health. This double identity as an autonomous publication and one that functions from a broad institutional perspective enriches the Revista/Journal and makes for its uniqueness.

In this new millennium, we face the urgent need to adapt the Revistal Journal to the demands of a new epidemiologic, social, economic, and political scenario and of technical and scientific advances that are coming at dizzying pace. We staff members of the Revista/Journal recognize the publication's diverse audience: public health professionals, researchers, general and specialized health practitioners, health services administrators, social scientists, nursing personnel, university professors, medical students, and a wide range of health technicians, all scattered throughout the vast territory of the Americas, from the Canadian tundra to the southern tip of South America. No single publication can fully cover the thematic range that such diversity demands. An enormous variety of specialty journals exist for this purpose. Instead, the editorial staff focuses on enhancing and strengthening those features of the Revista/Journal that make it a distinctive publication, unique among others of its kind.

In our conviction that statistics are of little value unless they serve as the springboard for moving forward from theory to practice, we seek to limit the publication of descriptive articles that provide local epidemiologic data, and to favor articles on interventions that appropriate evaluation methods have shown to be effective, or that describe new techniques and cast a new light on particular issues. We will also seek to include more pieces on the study and evaluation of health systems and services, from a qualitative, administrative, and economic point of view. In short, from now on the Revista/Journal will prioritize materials that, by their nature and subject matter, bear a direct or indirect influence on decision-making and the formulation of health policies. And with a view to providing our readers with research findings that are usable, one of our immediate goals will be to publish more 
pieces on current topics, more review articles with a Regional scope, and more editorials that will make it possible to view in a proper perspective the health problems that afflict our countries and to address in a comparative spirit the measures undertaken to combat those problems.

We are also aware that researchers make up only a portion-perhaps a minority-of the journal's audience, though not of its authors, obviously. Thus, we believe we also have a duty to serve the interests of those readers who deal with administrative and managerial aspects of public health. Along the same vein, there are some who tend to undervalue the social sciences and their theoretical and methodological techniques on the grounds that they rely on qualitative observations colored by subjectivity. Nevertheless, the social sciences cannot in any way be separated from public health. No one can deny the link between a person's physical and mental state and acquiring unhealthful habits, on the one hand, and, on the other hand, the material and social circumstances of that individual and the community. Unfortunately, relatively few of the publications indexed in the biomedical databases regularly carry articles on the relationship between health and the social sciences, with the exception of a few journals from Brazil and Mexico. Aware of how close this relationship really is, the Revista/Journal is striving to attract more contributions from experts in these disciplines.

As an antidote against falling behind the times in ideology and in practice, the Revista/Journal wants to kindle debate on policies, health interventions, and the health sector problems now confronting different countries. In order to do that, our journal will carry a greater number of opinion pieces, analytical commentaries, letters to the editor, critical observations, and other, similar resources. As we have in previous years, we will continue to publish special issues of the journal on subjects of particular importance; in the near future we plan to cover equity and health and also equity within the process of health sector reform.

There is a growing international interest in the public health problems of Latin America and the Caribbean, as shown by the increasing number of articles on that subject that have recently appeared in prestigious European and North American journals. Nevertheless, not knowing the English language is still a barrier for many monolingual persons in the Latin American scientific community who want to present the fruits of their research and to read the research performed by colleagues who speak their own language. For them, the Revista/Journal is an irreplaceable resource. Let us recall, in addition, that research is not an end in itself, except perhaps for those few researchers motivated just by an eagerness to reap academic honors. Rather, research is an exploration of reality, with a view to applying the available resources, which are often scarce, toward transforming that reality. Given that, it's therefore compulsory, from an ethical and human standpoint, that research results primarily be placed within the reach of the public who most stand to benefit. In the case of the Revista/Journal, a very large portion of that public is in Latin America. In comparison with other journals of its type, one of the unique advantages offered by the Revista/Journal is its trilingual character. Given these factors, we will seek soon to adopt measures to more completely meet the needs of monolingual readers. These steps might include article abstracts that are longer than traditional, in English to accompany articles in Spanish or Portuguese, and vice versa. Another measure might be subscriber-requested article translations, either one at a time or in the form of an annual supplementary publication. And beginning with this issue, you may note some small changes, such as the translation of each article title in the table of contents and the use of key words to facilitate database searches.

Up to this point, these are some of the immediate fruits of the joint efforts recently undertaken by our staff and the Editorial Board, of which we feel justifiably proud. The aim is to publish a journal that is more practical, more dynamic and stimulating, more geared toward analysis, debate, and the expression of differing points of view, always for the purpose of linking the results of research with policymaking. But our fundamental duty is to serve the community of persons who read our publication. To do that, we need to be familiar with those readers, to understand their needs and preferences, and to know to what extent we fulfill their expectations and help them carry out their work. With that goal in mind, we ask that you write to us and share your opinions, observations, and suggestions, to help us make the Revista/Journal the leading public health journal in the Region of the Americas. 